To the Editors:

\title{
Restraining tobacco - the Hydra headed monster
}

\author{
Ceylon Medical Journal 2014; 59: 72
}

The battle against the use of tobacco (in combustible form) has been a long drawn out one sapping the energy and resources of most tobacco-control advocates. With the revelation about hazards of 'side stream' or 'second hand' smoke three decades ago the need to protect 'innocent bystanders' gained centre stage of tobacco control efforts, pushing public smokers into the shadows. The habit of public smoking became stigmatized and smokers even ostracized in some public spaces.

Even with the knowledge that the tobacco related deaths globally is around six million, the pro-tobacco lobby has not given up its efforts to target the most vulnerable, namely the poor, the illiterate, the illicit substance and alcohol abusers, and more importantly the adolescents. The recent court case instituted by the Ministry of Health, Sri Lanka against the tobacco companies to display pictorial warnings of the deleterious effects of smoking was indeed a great victory. With increasing evidence that the adolescent brain has a greater susceptibility to the addictive qualities of nicotine the importance of protecting the adolescents has gained well deserved priority [1]. They undergo alterations in structure and function of the brain that make them more vulnerable to addiction and less responsive to nicotine replacement therapy [1].

The epidemiology of tobacco smoking also reveals important facts that have a greater bearing on policies to be adopted for prevention of tobacco use especially in combustible form. Most (80\%) of adult smokers began smoking daily before the age of 20 years [1]. Ninety percent of persons who purchase cigarettes for distribution to minors are under 21 [2]. Nearly $98 \%$ of tobacco related deaths are attributable to combustible products (including harm from second hand smoke) which dwarf other forms of tobacco use such as smokeless tobacco [3]. Attempts have been made to wean smokers away from the obnoxious habit by allowing nicotine in the form of chewing gum, nicotine replacement therapies and electronic nicotine delivery systems. More recently, battery operated nicotine delivery devices termed e-cigarettes that restore the feeling of smoking by vaporizing a liquid solution has been introduced to the market. Though promoted as a mode of delivery that reduces tobacco use one cannot be too sure about its long term effects as projected by public health campaigners. Some perceive such devices as Trojan horses which before long will threaten to reverse all what has been gained by anti-tobacco workers over the last few decades.

Though e-cigarettes have been introduced less than a decade ago they are gaining in popularity both in the West and the US. The suppliers are therefore now targeting the third world countries as well. With the avowed claim of 'harm reduction' some countries may be persuaded to accept this as the lesser of the two evils. Hence the importance of being forewarned about attempts at subtle introduction of this form of nicotine replacement.

The pro-tobacco lobby has warmly welcomed the introduction of e-cigarettes as the goal is not cessation of tobacco use but promotion of a 'harm reduction' slogan and thus reopen public spaces to perpetuate the private habit of smoking. Their exhilaration in anticipation of their success is so obvious that they are urging those who have given up combustible tobacco to 'rise from the ashes' and as 'cigarettes, you have met your match'! Smoke, like vapour from a glowing tip in a public space, will surely enhance the personal experience of 'smoking in public'. From such use it is only one small step to move on to using combustible tobacco. Further 'normalisation' of e-cigarette use could tempt former cigarette users to experiment with e-cigarettes and reinforce their declining addictive craving which may make them return to the old habit.

Having come a long way struggling to contain the menace of nicotine public health workers should not be betrayed by the seemingly innocuous introduction of e-tobacco. Let us hope that the Ministry of Health will be alive to this fact and take all necessary steps to prevent the introduction of e-cigarettes to this country. Forewarned is forearmed. Prevention is always better than cure!

\section{References}

1. Department of Health and Human Services. Preventing tobacco use among youth and young adults: a report of the Surgeon General, US, 2012 (http://www.surgeongeneral/ library/reports/preventing-youth-tobacco-use/\#Full\% 20Report).

2. Di Franza JR, Coleman M. Sources of Tobacco for youths in communities with strong enforcement of youth access laws. Tobacco Control 2001; 10: 323-8.

3. Zeller M, Hatsukami D. The Strategic Dialogue on Tobacco Harm Reduction: a vision and blue print for action in the US. Tobacco Control 2009; 18: 324-32.

Nanda Amarasekera, e-mail: <nanda_amar@live.com.>. 